\title{
Loneliness, Mindfulness and Hope: Empowering Rehabilitation Processes
}

\author{
Uzi Levi, Eyal Rosenstreich and Malka Margalit* \\ *Department of Behavioral Sciences, Peres Academic Center, Israel \\ *Corresponding author: Malka Margalit, Ph.D, Department of behavioral sciences, Peres Academic Center, Rehovot, Israel

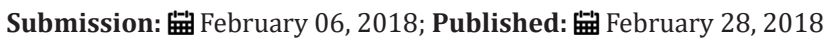

\begin{abstract}
The loneliness of individuals participating in rehabilitation programs may interfere with the success of these programs and limit their outcomes. The goals of this article are to explore the potential impact of two interventional approaches aimed to decrease the detrimental impacts of emotional and social withdrawal: mindfulness and the hope theory. The comparison of these intervention approaches and the focused survey of outcomes' research pinpointed attention on their complementary value. The nonjudgmental focus of the mindfulness approach on the present 'here and now', combined with the hopeful focus on future expectations in terms of goals and pathways, may reduce the loneliness experience and empower the individuals' effort during rehabilitation practices. This joint impact will be examined in future research of rehabilitation planning. World Health Organization (WHO) defines rehabilitation as a set of interventions designed to optimize functioning, to promote life quality and to reduce the disability impact in individuals with health concerns during their interactions with their environment [1].
\end{abstract}

\section{Introduction}

World Health Organization (WHO) The adverse emotional experience and loneliness among individuals during their participation in rehabilitation processes may affect the outcomes, since loneliness has been recognized as a potential indicator of threats to subjective well-being and as a risk factor to the health of children and adults at various age stages [2,3]. Loneliness may be experienced as a transient state during challenging periods, but it may also indicate a long-lasting perception with adverse physical and mental health and an unhealthy lifestyle [4] An example to recent public growing awareness and its significance is reflected in the UK's Campaign to End Loneliness, following the survey that a quarter of UK adults report being lonely and $6 \%$ of those report being lonely most of the time [5].

Loneliness has been typically described as a subjective distressing experience. The most common conceptualization is focused on the discrepancy perspective $[6,7]$. According to this conceptualization, loneliness reflects a discrepancy between the quantity and the quality of relationships that people have versus the relationships that they want [8]. In fact, the loneliness experience is focused on three major components: the perceptions of the self, the assessment of the person's environments, and the evaluation of the interrelations' qualities. Considering the health-related risks of lonely individuals, that may interfere with the success of rehabilitation planning; we present the potential joint effect of two current interventional approaches: The mindfulness and the hope theory interventions. We shall conclude by comparing them and proposing their integration and future research.

\section{Mindfulness}

meditation is a practice originated from the Buddhist tradition, defined as the awareness of an object as a whole [9] or as "bringing to the present the awareness of things that you have learned" [10] and is one practice of the Buddhist Eightfold Path aimed at reducing suffering. Western mindfulness preserved some of its Buddhist origin's core concepts [11] and was conceptualized as the cultivation of a moment to moment awareness of one's own emotions, state of mind, and surroundings [12]. Accordingly, in a typical practice of mindfulness, the practitioner is guided to focus on his/hers breathing, to attend and evaluate his/hers feelings in a non-judgmental and accepting manner, and to express gratitude for the things one have in his/hers life [13]. The canonic intervention is the Mindfulness Based Stress Reduction [14], which consists of eight 2-hours weekly sessions, accompanied by a 30-minute daily home practice, typically guided by recorded instructions [12]. As implied by its name, this intervention was originally aimed at reducing stress, typically (but not exclusively) among chronic pain patients. Over the years, mindfulness practice has been found to have beneficial effects on mood, psychological wellbeing and physical health [15], with shorter interventions reported to be as effective as the MBSR; three 30-minutes practice sessions were reported to reduce pain and anxiety [16] and similar effectiveness 
was found when mindfulness instructions were delivered online [17].

The question whether mindfulness may reduce loneliness was recently addressed. Creswell [18] reported that mindfulness practice decreased levels of loneliness among older adults, and that this effect was mediated, to some extent, by the suppression of pro-inflammatory gene activity. In another study, [19] found that mindfulness practice moderated the effects of loneliness on academic achievements among first-year college students, such that whereas high levels of loneliness accompanied lower grades in the control group, no association between loneliness and achievements was evident in the mindfulness group. Finally, the impact of mindfulness-based cognitive therapy in reducing loneliness among patients with HIV was demonstrated [20]. However, the processes through which mindfulness practice reduces loneliness are yet unclear. We propose three possible mechanisms. First, loneliness is associated with poor control over attention, such that attention is over-captured by negative social stimuli [21]. Mindfulness practice has been well established to improve control over attention [22] hence this may be a plausible mechanism of influence. Second, thoughts of social exclusion have been argued to exhaust cognitive self-control resources, thus manifested in prevention rather than goal-promoting behavior [23]. In contrast, mindfulness practice has been demonstrated to be associated with greater self-control and adaptive goal setting [24], hence may be a viable mechanism of the mindfulness-loneliness connection. Finally, loneliness is strongly associated with negative affect and depressive symptoms [25]. Mindfulness, on the other hand, has been demonstrated to reduce negative affect and to increase hope through the reduction of cognitive distortions [26]. Therefore, such cognitive-affective mechanism may also account for the effects of mindfulness on loneliness. Nonetheless, mindfulness practice does not entail prospective introspection. That is, the cultivation of moment-tomoment awareness [27] may not focus on the future expectations, which are in the essence of the hope theory.

\section{Hope Theory}

Loneliness deals with the memories of adverse past experiences, and the tendency to avoid similar frustrating experiences in the present. The lonely persons tend to focus their thoughts on themselves and their disappointing and hurting relationships with others. The hope theory does not deny the painful experiences, but ameliorate them through introducing the future perspectives. It targets desired goals and treats possible barriers in the future, exploring paths in order to promote control. Thus, hope may play an important role in coping with loneliness and promoting psychological health. Strong associations between hope and different aspects of wellbeing were demonstrated in a remarkable amount of studies, emphasizing the importance of hopeful thinking for change promotion and effective intervention [28-32]. Snyder's theory of hope [33] presented the pursuit of goals as the organizing principle of human behavior. Snyder defined hope as "the perceived capability to derive pathways to desired goals, and motivate oneself via agency thinking to use those pathways"
[32]. Hope is generally conceptualized as an adaptive psychological strength that can be acquired. It helps individuals to identify and attain their goals, which can have both direct and indirect positive impact. The most direct influence that hope has on well-being comes from the positive orientation and expectations toward the future. Hopeful thought reflects the belief that human actions are goals' directed. Indeed, life adversities may freeze our thoughts and emotions, and focus them on the present hard ships and/or past frustrations. The move to identifying of future goals may empower personal resources, and enhance effective coping. The ability to produce a mental representation of ourselves and our environment is the basis of the two interrelated cognitive processes of the Hope Theory [32]: Pathway Thinking and Agency Thinking.

A. Pathway Thinking involves the planning of plausible routes to a goal, the consideration of possible barriers, and the planning how to overcome them.

B. Agency thinking is the ability to initiate and sustain movement along pathways until the goal is reached.

Research on the hope among children and adults [30,3436] revealed that the levels of hope predicted wellbeing and success in different domains. Hope interventions were developed, demonstrating that hopeful thinking is malleable and can be enhanced through extended (three months or a year) as well as short-term training (a single meeting) [28]. From exposer to learning and training experience that included the use of simulations and mental rehearsal individuals learn to adopt hopeful thinking [37]. Even more important, hope has been examined as a predictor and mediator of treatment success. Data suggest that individuals with high hope benefited more from intervention than those with low hope. These results proposed that hope may be a supportive and empowering mechanism in various interventions.

\section{Conclusion and Future Direction}

Taken altogether, mindfulness and hope share some of their core constructs, as both facilitate a non-judgmental perspective on the self, by using simulations and mental rehearsal. Mindfulness promotes a general non-judgmental atmosphere to one's current state and feelings, whereas hope promotes a focus on one's future goals regardless of past difficulties and challenges. Furthermore, both concepts empower the sense of self-efficacy and the ability to face obstacles and barriers. Yet, mindfulness and hope propose complementary processes. Whereas mindfulness addresses the present state of the self, by increasing moment to moment awareness, hope enhances the awareness to one's future goals, the pathways to reach them with specific plans to overcome obstacle and barriers, thus endorsing feelings of autonomy and competence. Therefore, mindfulness can be regarded as a promoter of compassion perspective on current state of oneself, while hope can be consider as a motivator for moving forward and focusing effort to achieve goals. We propose that a combined intervention may empower rehabilitation processes in general and especially during periods of increased loneliness and anxious self-doubt that often accompany the extended rehabilitation experiences. 
Such an interventional approach may include two major steps. First, mindfulness practice should be employed to reduce negative thoughts and feelings and to strengthen intra-connectedness with the self. This can help people that suffer from loneliness to shift their attention and empower their personal strengths. Then, hope intervention in the second step may provide a motivating focus on goals for the future and the agencies to achieve them. To conclude, the processes underlying mindfulness meditation may bolster the effectiveness of hope intervention, and successful goal setting may increase one's positive experience and perception of the self, and thus, in a reciprocal manner, may benefit with one's ability to endorse the mindfulness awareness. Both approaches will empower the individual's struggles with disabilities, and motivate their engagement in the rehabilitation progression. Future studies are needed to experiment the joint impact of hope and mindfulness interventions and to explore approaches to embrace them in different rehabilitation programs.

\section{References}

1. http://apps.who.int/iris/bitstream/10665/254506/1/978924154997 4-eng.pdf?ua=1

2. Newall NEG, Menec VH (in press) Loneliness and social isolation of older adults:Why it is important to examine these social aspects together. Journal of Social and Personal Relationships doi: $10.1177 / 0265407517749045$.

3. Nishimura T, Murakami T, Sakurai $\mathrm{S}$ (in press) Do not overlook lonely children. Journal of Social and Personal Relationships doi: $10.1177 / 0265407517701840$

4. Richard A, Rohrmann S, Vandeleur CL, Schmid M, Barth J, et al. (2017) Loneliness is adversely associated with physical and mental health and lifestyle factors: Results from a Swiss national survey. PLoS One 12(7): e0181442.

5. Victor CR, Yang K (2012) The prevalence of loneliness among adults: A case study of the United Kingdom. J Psychol 146: 85-104.

6. Dykstra PA, Fokkema T (2007) Social and emotional loneliness among divorced and married men and women: comparing the deficit and cognitive perspectives. Basic and Applied Social Psychology 29(1): 1-12.

7. Peplau LA, Perlman D (1982) Perspectives on loneliness. In: Peplau LA Perlman D (Eds.), Loneliness: A sourcebook of current theory, research and therapy. Wiley, New York, UK, pp. 1-18.

8. De Jong-Gierveld J (1987) Developing and testing a model of loneliness J Pers Soc Psychol 53(1): 119-128.

9. Eltschinger V (2014) The four nobles' truths and their 16 aspects: on the dogmatic and soteriological presuppositions of the buddhist epistemologists' views on niścaya. Journal of Indian Philosophy 42(2): 249-273.

10. Dalai Lama, Ekman P (2008) Emotional awareness: Overcoming the obstacles to psychological balance and compassion. In: Dalai Lama, Ekman P (Eds.), Emotional awareness: Overcoming the obstacles to psychological balance and compassion. Holt, Ney York, USA.

11. Kudesia RS, Nyima VT (2015) Mindfulness contextualized: An integration of Buddhist and neuropsychological approaches to cognition. Mindfulness 6(4): 910-925.

12. Shapiro SL, Carlson LE (2009) The art and science of mindfulness: Integrating mindfulness into psychology and the helping professions. In: Shapiro SL, Carlson LE (Eds.), The art and science of mindfulness: Integrating mindfulness into psychology and the helping professions.
APA publications, USA.

13. Kok BE, Singer $T$ (2017) Phenomenological fingerprints of four meditations: differential state changes in affect, mind-wandering, metacognition, and interoception before and after daily practice across 9 months of training. Mindfulness 8(1): 218-231.

14. Kabat-Zinn J (2003) Mindfulness-based practices in context: Past, present, and future. Clinical Psychology: Science and Practice 10(2): 144-156.

15. Geiger PJ, Boggero IA, Brake CA, Caldera CA, Combs HL, et al. (2016) Mindfulness-based interventions for older adults: a review of the effects on physical and emotional well-being. Mindfulness 7(2): 296-307.

16. Zeidan F, Gordon NS, Merchant J, Goolkasian P (2010) The effects of brief mindfulness meditation training on experimentally induced pain. J Pain 11(3): 199-209.

17. Krusche A, Cyhlarova E, King S, Williams JMG (2012) Mindfulness online: a preliminary evaluation of the feasibility of a web-based mindfulness course and the impact on stress. BMJ Open 2(3): 1-6.

18. Creswell JD, Irwin MR, Burklund LJ, Lieberman MD, Arevalo JM, et al (2012) Mindfulness-Based Stress Reduction training reduces loneliness and pro-inflammatory gene expression in older adults: A small randomized controlled trial. Brain Behav Immun 26(7): 1095-1101.

19. Rosenstreich E, Margalit M (2015) Loneliness, mindfulness, and academic achievements: A moderation effect among first-year college students. The Open Psychology Journal 8(Suppl 2-M11): 138-145.

20. Samhkaniyan E, Mahdavi A, Mohamadpour S, Rahmani S (2015) The effectiveness of mindfulness-based cognitive therapy on quality of life and loneliness of women with HIV. J Med Life 8(Spec Iss 4): 107-113.

21. Cacioppo S, Balogh S, Cacioppo JT (2015) Implicit attention to negative social, in contrast to nonsocial, words in the Stroop task differs between individuals high and low in loneliness: Evidence from event-related brain microstates. Cortex 70: 213-233.

22. Watier N, Dubois M (2016) The effects of a brief mindfulness exercise on executive attention and recognition memory. Mindfulness 7(3): 745753.

23. Park J, Baumeister RF (2015) Social exclusion causes a shift toward prevention motivation. Journal of Experimental Social Psychology 56: 153-159.

24. Friese M, Hofmann W (2016) State mindfulness, self-regulation, and emotional experience in everyday life. Motivation Science 2(1): 1-14

25. Hawkley L, Cacioppo J (2010) Loneliness matters: A theoretical and empirical review of consequences and mechanisms. Annals of Behavioral Medicine 40(2): 218-227.

26. Sears S, Kraus S (2009) I think therefore I om: Cognitive distortions and coping style as mediators for the effects of mindfulness meditation on anxiety, positive and negative affect, and hope. J Clin Psychol 65(6): 561573.

27. Dam NTV, Vugt MK, Vago DR, Schmalzl L, Saron CD, et al. (2018) Mind the hype: a critical evaluation and prescriptive agenda for research on mindfulness and meditation. Perspect Psychol Sci 13(1): 36-61.

28. Cheavens JS, Guter MM (2018) Hope Therapy. In: Gallagher MW, Lopez SJ (Eds.), The Oxford Handbook of hope. NY: Oxford University Press, UK, pp. 133-142.

29. Feldman DB, Davidson OB, Margalit M (2015) Personal resources, hope, and achievement among college students: the conservation of resources perspective. Journal of Happiness Studies 16(3): 543-560.

30. Gallagher MW, Lopez SJ (2018) The Oxford Handbook of hope NY: Oxford University Press, UK. 
31. Hedayati M, Khazaei M (2014) An investigation of the relationship between depression, meaning in life and adult hope. Procedia-Social and Behavioral Sciences 114: 598-601.

32. Snyder CR (2002) Hope theory: Rainbows in the mind. Psychological Inquiry 13(4): 249-275.

33. Snyder CR (1995) Conceptualizing, measuring, and nurturing hope. Journal of Counseling \& Development 73(3): 355-360.

34. Ben-Naim S, Laslo-Roth R, Einav M, Biran H, Margalit M (2017) Academic self-efficacy, sense of coherence, hope and tiredness among college students with learning disabilities. European Journal of Special Needs Education 32(1): 18-34.
35. Levi U, Einav M, Raskind I, Ziv O, Margalit M (2014) Academic expectations and actual achievements: the roles of hope and effort European Journal of Psychology of Education 29(3): 367-386.

36. Margalit M (2012) Lonely children and adolescents: Self perceptions, social exclusion and hope. In: Margalit M (Ed.), Lonely children and adolescents: Self perceptions, social exclusion and hope. Springer, New York, UK.

37. Feldman DB, Davidson OB, Margalit M (2012) Promoting hope, sense of coherence and self-efficacy in college: The salutogenic paradigm. In: Mayer CH, Krause C (Eds.), Exploring mental health: Theoretical and empirical discourses on salutogenesis. Berlin: Pabst Science Publishers, Germany, pp. 57-72. (c) (i) Creative Commons Attribution 4.0 International License

For possible submissions Click Here

\section{Submit Article}

EPMR Examines in
Physical Mediciane
\& Rehabobilitation

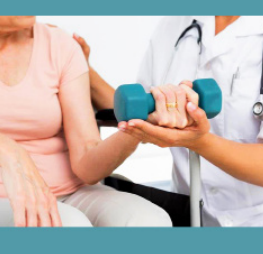

Examines in Physical Medicine and Rehabilitation Open Access

\section{Benefits of Publishing with us}

- High-level peer review and editorial services

- Freely accessible online immediately upon publication

- Authors retain the copyright to their work

- Licensing it under a Creative Commons license

- Visibility through different online platforms 